\title{
Validity of the Vesikari Score for the Assessment of Pediatric Acute Gastroenteritis in Correlation with Nutritional and Socioeconomic Influences
}

\author{
Nehal M El Koofy ${ }^{1} \cdot$ Nabil A. Mohsen ${ }^{1} \cdot$ Mohamed A. Elmonem ${ }^{2} \cdot$ Rehab H. Zawam $^{1} \cdot$ Sara Tarek $^{1}$
}

Received: 16 April 2021 / Accepted: 22 June 2021 / Published online: 30 July 2021

(c) Dr. K C Chaudhuri Foundation 2021

To the Editor: We recruited 348 infants/children ( 2 mo-5 y) with acute gastroenteritis at the Children's Hospital, Cairo University, Cairo. Children with food allergies, malabsorption syndromes, inborn errors of metabolism, chronic diseases, and congenital GIT malformations were excluded. We compared the Vesikari Clinical Scoring System (VCSS) [1] to the WHO dehydration score [2] in correlation to malnutrition and socioeconomic status (SES) classified by El-Gilany modified score [3].

Recruited infants/children were $14.7 \pm 12.6$ mo old and 211/348 (60.6\%) were boys; 193 (55.5\%) were breast-fed, 107 (30.7\%) were artificially fed, and 48 (13.8\%) were both. Fifteen families $(4.3 \%)$ were categorized as very-low-SES quartile, $206(59.2 \%)$ as low, $121(34.8 \%)$ as moderate, and $6(1.7 \%)$ as high. A total of 195 families (56\%) lived in urban areas, $126(36.2 \%)$ lived in slums, and $27(7.8 \%)$ lived in rural areas. There were $74.4 \%$ families that had pure water supply and sanitary sewage system. In $63.6 \%$ families, both parents were educated; $18.3 \%$ had one educated parent, and in $18.1 \%$ both were illiterate. Children having normal weight and height were $73.9 \%$ and $69.3 \%$, respectively, while $26 \%$ had wasting according to WHO $z$ scores; 68/221 (30.1\%) with lower SES (very low and low quartiles) had wasting, while 23/127 (18.1\%) with higher SES (moderate and high quartiles) had wasting $(p=0.012)$.

At presentation, 35 (10\%) were lethargic, 112 (32.2\%) had sunken eyes, 18 (5.2\%) had very slow skin pinch, and $19(5.5 \%)$ drank poorly. Using the WHO dehydration score, $39(11.2 \%)$ had severe dehydration, 75 (21.6\%) had mild dehydration, while 234 (67.2\%) had no dehydration.

Sara Tarek

sara.tarek2310@outlook.com

1 Pediatric Gastroenterology Unit, Department of Pediatrics, Faculty of Medicine, Cairo University, Cairo 11562, Egypt

2 Department of Clinical and Chemical Pathology, Faculty of Medicine, Cairo University, Cairo, Egypt
Alternatively, using VCSS, gastroenteritis was severe in 256 (73.6\%), moderate in $88(25.3 \%)$, and mild in $4(1.1 \%)$. Attack severity by VCSS strongly correlated with the dehydration degree using the WHO dehydration score $(R=0.372$, $p<0.0001)$. A VCSS of $15 / 20$ or above has the highest area under the ROC curve to detect dehydration with $82 \%$ specificity and 53\% sensitivity. Through multivariate regression, artificial feeding was a significant predictor of severe diarrhea according to VCSS $(p=0.023)$ and a borderline predictor of severe dehydration by the WHO dehydration score $(p=0.067)$. Residency in slums was a significant predictor of both $(p<0.0001)$.

Although the WHO dehydration score gives a more objective evaluation of dehydrated children, the VCSS has a satisfactory performance. Artificial feeding, stunting, living in slums, and parental illiteracy are important risk factors for acute gastroenteritis severity in Egypt.

\section{Declarations}

Conflict of Interest None.

\section{References}

1. Ruuska T, Vesikari T. Rotavirus disease in Finnish children: use of numerical scores for clinical severity of diarrhoeal episodes. Scand J Infect Dis. 1990;22:259-67.

2. World Health Organization. The treatment of diarrhea: A manual for physicians and other senior health workers, 4th version.WHO/ FCH/CAH/05.1. World Health Organization, Geneva 2005. Available at: https://whqlibdoc.who.int/publications/2005/9241593180. pdf. Accessed on 28th April 2020.

3. El-Gilany A, El-Wehady A, El-Wasify M. Updating and validation of the socioeconomic status scale for health research in Egypt. East Mediterr Health J. 2012;18:962-8.

Publisher's Note Springer Nature remains neutral with regard to jurisdictional claims in published maps and institutional affiliations. 